\title{
Avaliação da qualidade de vida relacionada à visão em crianças com catarata congênita bilateral
}

\author{
Assessing vision-related quality of life in children \\ with bilateral congenital cataracts
}

\author{
Marcia Caires Bestilleiro Lopes ${ }^{1}$ \\ Solange Rios Salomão ${ }^{2}$ \\ Adriana Berezovsky ${ }^{3}$ \\ Marcia Beatriz Tartarella ${ }^{4}$
}

Trabalho realizado no Departamento de Oftalmologia da Universidade Federal de São Paulo - UNIFESP - São Paulo (SP) - Brasil - Instituto da Catarata Congênita.

${ }^{1}$ Pós-graduanda (Mestrado) e responsável pelo Ambulatório de Estimulação Visual Precoce da Universidade Federal de São Paulo - UNIFESP - São Paulo (SP) Brasil.

${ }^{2}$ Livre-docente, Professora Associada, Chefe do Setor de Eletrofisiologia Visual Clínica do Departamento de Oftalmologia da UNIFESP - São Paulo (SP) - Brasil.

${ }^{3}$ Doutora em Ciências Visuais; Professora Adjunta do Departamento de Oftalmologia da UNIFESP - São Paulo (SP) - Brasil.

${ }^{4}$ Doutora, Chefe do Ambulatório de Catarata Congênita do Departamento de Oftalmologia da UNIFESP - São Paulo (SP) - Brasil.

Endereço para correspondência: Marcia Caires Bestilleiro Lopes. Avenida Paulista, 2.001 - Cj. 1.001 - São Paulo (SP) CEP 01311-931

E-mail: marciacblopes@gmail.com

Recebido para publicação em 11.09.2008

Última versão recebida em 04.05.2009

Aprovação em 20.05.2009

Bolsa CAPES - Coordenação de Aperfeiçoamento de Pessoal de Nível Superior do Ministério da Educação Governo Federal / (33009015024P-0 Medicina/Oftalmologia - UNIFESP), 2006.

Nota Editorial: Depois de concluída a análise do artigo sob sigilo editorial e com a anuência do Dr. Mauro Waiswol sobre a divulgação de seu nome como revisor, agradecemos sua participação neste processo.

\section{RESUMO}

Objetivo: Avaliar a qualidade de vida relacionada à visão em crianças com catarata congênita bilateral, utilizando o Questionário de Função Visual Infantil (QFVI). Métodos: O QFVI possui duas diferentes apresentações: crianças menores e maiores de 3 anos, sendo dividido em seis domínios: saúde geral, saúde geral da visão, competência, personalidade, impacto familiar e tratamento. O QFVI foi aplicado aos pais/cuidadores/responsáveis de crianças com catarata congênita bilateral do Instituto da Visão da Universidade Federal de São Paulo. As notas encontradas nos domínios foram comparadas entre os grupos controle - crianças com visão normal $(n=32$, média da idade=38 meses; $d p=17,3)$ e experimental crianças com catarata congênita (menores de 3 anos, $n=19$, idade média=14,6 meses; $d p=10,7$ e maiores de 3 anos, $n=18$, idade média=4,4 anos; $\mathrm{dp}=1,5$, alocados segundo o grau de comprometimento visual em $\mathrm{n}=16$ sem deficiência visual; $n=10$ - deficiência visual leve; $n=11$ - deficiência visual grave). Para a análise estatística foram utilizados os testes t e análise de variância (ANOVA). Resultados: $O$ grupo experimental apresentou redução estatisticamente significativa em todos os domínios do questionário, quando comparado ao grupo controle. O domínio competência apresentou-se com baixa nota havendo redução estatisticamente significante de acordo com a gravidade da deficiência visual (ANOVA F 5,1, p=0,01; teste de Tukey $\mathrm{p}<0,01)$, assim como a nota composta total (ANOVA F 5,4, p=0,01; teste de Tukey p=0,01/0,05). Conclusão: A catarata congênita bilateral influencia na qualidade de vida relacionada à visão em crianças, confirmada pelos baixos valores obtidos nos domínios estudados, mais evidentemente no domínio competência. O QFVI mostrou-se um importante instrumento para avaliar e mensurar o impacto do comprometimento visual causado pela catarata congênita bilateral na qualidade de vida.

Descritores: Qualidade de vida; Catarata/congênito; Questionários; Visão; Baixa visão; Criança; Cuidadores

\section{INTRODUÇÃO}

A qualidade da visão é parte integral da qualidade de vida de todos os indivíduos $^{(1)}$. A visão é um dos mais importantes sentidos no desenvolvimento normal da criança ${ }^{(2)}$. O comprometimento dessa via pode causar dificuldades nas habilidades de vida diária, no desenvolvimento neuropsicomotor normal e na relação familiar ${ }^{(3-9)}$. A catarata congênita bilateral é uma causa frequente de cegueira na infância, responsável por cerca de 10 a $30 \%$ dos casos, variando entre diferentes regiões do mundo ${ }^{(8,10)}$. 
Os instrumentos para a avaliação da qualidade de vida relacionada à visão em pacientes adultos são amplamente utilizados para pesquisas em oftalmologia. No entanto, no grupo infantil, seu uso é limitado, pois envolve processos e etapas do crescimento que dependem do desenvolvimento normal da criança $^{(11)}$. Para isto, foi desenvolvido o Questionário de Função Visual Infantil (2) (QFVI). Sua versão no idioma português foi validada durante o estudo original, quando foi traduzido para o português-brasileiro, adaptado para a realidade cultural e econômica, retraduzido para o inglês americano por profissional especializado (tradutor juramentado) e comparado com a versão original em inglês com grande similaridade e finalmente aplicado em crianças de visão normal.

O QFVI apresenta-se em duas versões de acordo com a faixa etária, contendo 35 questões para menores de 3 anos (QFVI - 3) e 40 questões para maiores de 3 anos (QFVI - 7), abordando diversos aspectos sobre a qualidade da função visual infantil, sendo dividido em seis domínios: Saúde Geral; Saúde Geral da Visão; Competência; Personalidade; Impacto familiar e Tratamento (Anexos 1 e 2).

O presente estudo tem como objetivo avaliar a qualidade de vida relacionada à visão pela aplicação do QFVI - 3 e QFVI - 7.

\section{MÉTODOS}

Este estudo prospectivo observacional transversal foi realizado no período de fevereiro de 2006 a março de 2007, no Departamento de Oftalmologia da UNIFESP. O estudo seguiu os princípios da Declaração de Helsinque e foi analisado e aprovado pelo Comitê de Ética em Pesquisa da Universidade Federal de São Paulo/Hospital São Paulo, sob o número 1.641/ 04 em 13 de abril de 2005.

Foram convidados a participar deste estudo pais/responsáveis/cuidadores de 69 crianças alocados em dois grupos: experimental e controle. O grupo experimental teve o seguinte critério de inclusão: diagnóstico de catarata congênita bilateral com ou sem tratamento prévio (cirurgia, óculos, oclusão), com idade inferior a 7 anos, estas eram subdivididas em menores de 3 anos e crianças de 3 a 7 anos, além de ausência de alterações neurológicas ou outras patologias associadas. O grupo controle tem os seguintes critérios de inclusão: idade até 7 anos, boa saúde geral, exame oftalmológico normal, ausência de queixas visuais e ausência de alterações neurológicas ou outras patologias associadas. A composição e característica de cada grupo encontram-se descrita na tabela 1.

As crianças do grupo experimental foram subdivididas de acordo com a gravidade da deficiência visual. O limite de normalidade da acuidade visual variou de acordo com a idade. Para classificar a acuidade visual e também sua variação, todas as medidas foram convertidas em uma classificação única (logMAR), com a escala variando de sem deficiência visual à deficiência visual grave. A visão foi considerada normal quando constatada a visão adequada e esperada para a idade cronológica da criança, de acordo com o método empregado para medida da AV - cartões de acuidade de Teller ou potencial visual evocado de varredura ${ }^{(12)}$, como, deficiência visual leve para redução de até $0.1 \log$ MAR da visão normal para a idade, até a perda visual leve, para visão que variasse de 0.2 a 0.3 $\log$ MAR, abaixo do limite de tolerância normal para a idade. A deficiência visual moderada, para redução de 0.4 a 0.9 $\log$ MAR, abaixo do limite de tolerância normal para a idade e deficiência visual grave para redução de $1.0 \log$ MAR, do limite de tolerância normal para a idade ${ }^{(11)}$. A composição e característica de cada grupo encontram-se descrita na tabela 2, sendo leve, os pacientes com deficiência visual limite e leve e o grupo denominado grave as crianças com comprometimento moderado e grave.

O QFVI foi aplicado e respondido por pais/responsáveis/ cuidadores, que convivessem e cuidassem das crianças ( $\mathrm{Ta}$ bela 3). A administração do questionário foi feita sempre pelo mesmo entrevistador (MCBL), com perguntas realizadas individualmente, seguindo a sequência do mesmo.

Na análise do QFVI, nota igual a 100 (cem) indica "melhor", 0 (zero) indica "pior" qualidade de vida. A nota de cada domínio foi então definida como a média das notas dos itens que pertencem a ela. Itens classificados como "não se aplica", assim como itens não respondidos, são simplesmente omitidos da média. Detalhes de como realizar a pontuação para cada subescala e a pontuação total, chamada de nota composta total, são descritos nos quadros 1A e B (http://www.retinafoundation.org).

Para a análise estatística, a comparação entre os grupos maiores e menores de três anos foi utilizada o teste t-Student não pareado, já a análise entre os três grupos de deficiência visual, foi utilizada a análise de variância (ANOVA), sendo o valor de significância estabelecido como $\mathrm{p}<0,05$.

\section{RESULTADOS}

A nota composta total da qualidade de vida relacionada à visão medida pelo QFVI mostrou-se reduzida no grupo experimental, quando comparado ao grupo controle. Todos os domínios foram estatisticamente reduzidos no grupo experimental, quando comparado ao grupo controle ( $p<0,05$ - Figura 1), sendo os domínios de maior comprometimento o impacto da família e competência.

Na comparação dos grupos de deficiência visual, os domínios com as notas estatisticamente reduzidas foram, competência $(\mathrm{F}=5,1, \mathrm{p}=0,01)$ e nota composta total $(\mathrm{F}=5,3, \mathrm{p}=0,01)$.

Quando comparados entre si, o grupo de deficiência visual grave apresentou redução estatisticamente significativa quando comparado ao grupo sem deficiência visual, no domínio competência $(\mathrm{p}=0,01)$ e nota composta total $(\mathrm{p}=0,01)$ - (Figura 2$)$.

\section{DISCUSSÃO}

As crianças com catarata congênita bilateral em ambas as faixas etárias, menores e maiores de 3 anos, apresentaram 
Anexo 1 - QFVI - 3 - Questionário de Função Visual Infantil (Versão para crianças menores de 3 anos)

\section{Paciente \#}

Esta página de rosto será descartada. É usada somente para controle enquanto você estiver no consultório médico.

Os exames oculares não medem como a visão de uma (sua) criança afeta suas atividades diárias e o seu bem-estar geral. Nós estamos aplicando um questionário para medir como os problemas visuais afetam a (sua) criança na vida e como estes problemas visuais afetam suas famílias.

Nós não daremos qualquer informação sobre você ou seu(ua) filho(a) para qualquer outra pessoa.

\section{Instruções}

Por favor, leia ou ouça cada pergunta cuidadosamente;

É importante que você responda a todas as questões;

Tente optar por uma única resposta para cada pergunta;

Se seu(ua) filho(a) usa óculos ou oclusão (tampão), tente pensar em suas situações típicas do dia-a-dia enquanto responde às questões.

Por favor, responda às questões a seguir sobre a saúde e a visão do seu(ua) filho(a):

1. Em geral, a saúde geral de seu(ua) filho(a) é:
( ) Excelente
( ) Muito Boa
( ) Boa
( ) Razoável
( ) Ruim

2. No momento, a visão de seu(ua) filho(a) quando está com os dois olhos abertos é:

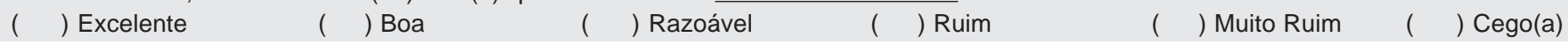

3. Se o(a) seu(ua) filho(a) tem problema visual somente em um olho, a visão de seu(ua) filho(a) no olho com problema é:

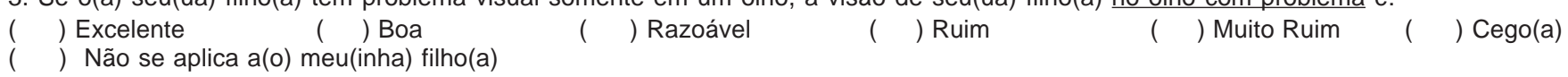

4. Você se preocupa com a visão de seu(ua) filho(a)?

( ) Nunca ( ) Raramente ( ) Às vezes ( ) Frequentemente ( ) Sempre

5. Quanto tempo você gasta para cuidar da visão de seu filho (tais como: consultas com oftalmologista, oclusão ou tampão, colírios, terapia)?

( ) Uma vez ao mês ou menos (ou nunca) ( ) Uma vez por semana

) Poucas horas do dia ( ) A maior parte do dia

( ) Uma vez por dia

6. O tempo que você gasta com a visão de seu(ua) filho(a) (consultas com o oftalmologista, oclusão, colírios, terapia) toma o tempo que você gostaria de gastar com seus outros filhos ou marido/esposa?
( ) Nunca
( ) Raramente
( ) Às vezes
( ) Frequentemente
( ) Sempre

7. Você e os outros membros da sua família (marido/esposa ou pais) discutem sobre os cuidados médicos que seu(ua) filho(a) está recebendo ou sobre o tratamento que o médico prescreveu?
( ) Nunca
( ) Raramente
( ) Às vezes
( ) Frequentemente
( ) Sempre

Nós gostaríamos de saber como você se sente sobre a visão de seu(ua) filho(a).

Por favor indique o quanto você concorda com as perguntas a seguir:

$\begin{gathered}\text { Discordo } \\ \text { plenamente }\end{gathered}$
Discordo $\begin{gathered}\text { Não estou } \\ \text { certo }\end{gathered}$ Concordo $\begin{gathered}\text { Concordo } \\ \text { plenamente }\end{gathered} \begin{gathered}\text { Não se aplica a } \\ \text { meu(inha) filho(a) }\end{gathered}$

8. Me incomoda quando outras pessoas comentam sobre a visão ou os olhos de meu(inha) filho(a) quando o(a) levo a algum lugar.

9. Meu(inha) filho(a) se sente diferente das outras crianças.

10. Eu percebo que as outras crianças olham para o(a) meu(inha) filho(a).

11. Meu(inha) filho(a) gosta de visitar os parentes (família).

12. Meu(inha) filho(a) fica zangado(a) ou frustrado(a) por causa de seu problema visual.

13. Tenho receio se meu(inha) filho(a) conseguirá, ou não será capaz, de ler, ver TV, ou dirigir um carro.

14. Meu(inha) filho(a) fica bem sozinho(a) ou com outras crianças e amigos.

Como a visão de seu(a) filho(a) afeta as atividades dele(a)?

Por favor, indique o quanto são difíceis para o seu(ua) filho(a) as atividades descritas abaixo, por causa do seu problema visual:

Sem dificuldade
por causa
da visão

15. Meu(inha) filho(a) consegue alimentar-se sozinho(a).

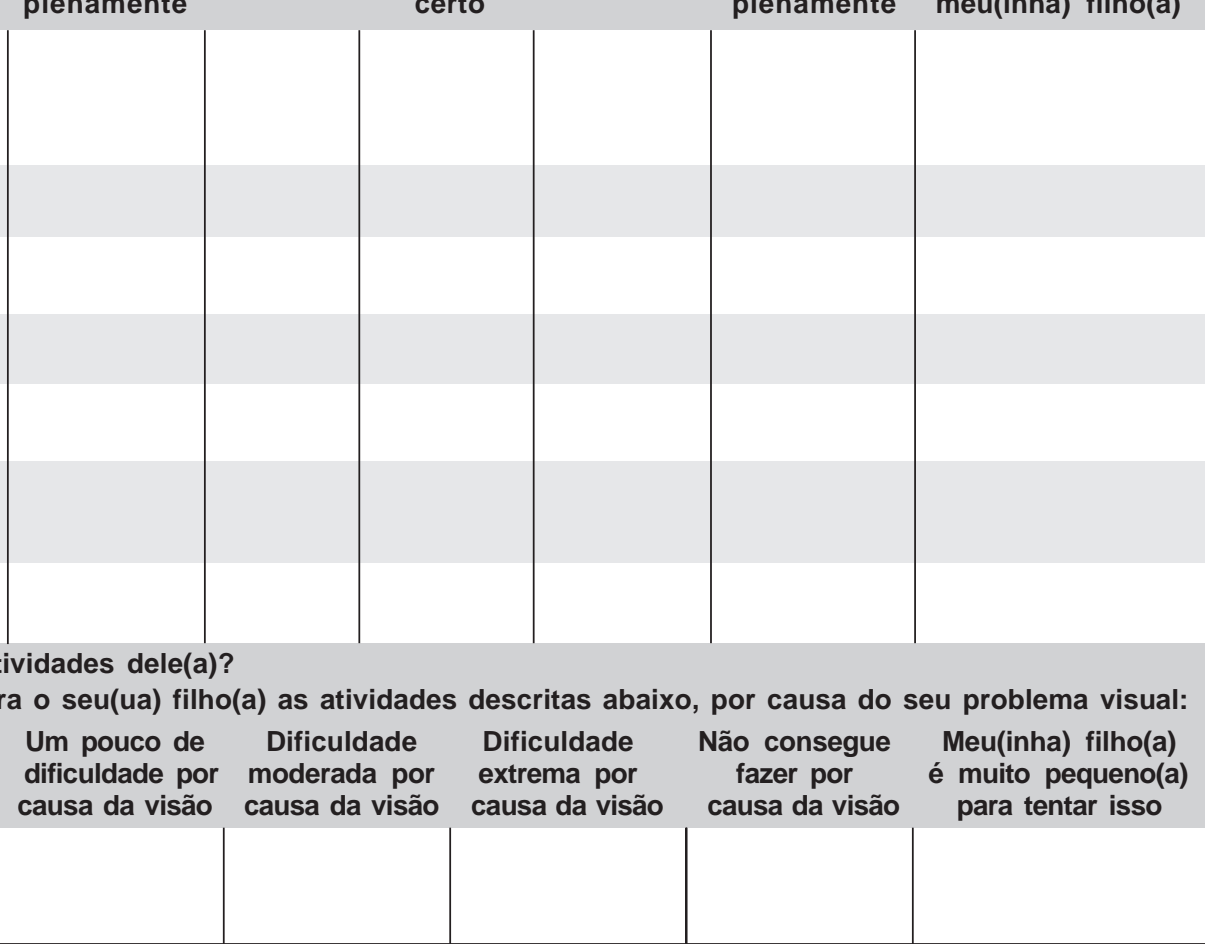


(Continuação) Anexo 1 - QFVI - 3 - Questionário de Função Visual Infantil (Versão para crianças menores de 3 anos)

Como a visão de seu(a) filho(a) afeta as atividades dele(a)?

Por favor, indique o quanto são difíceis para o seu(ua) filho(a) as atividades descritas abaixo, por causa do seu problema visual:

$\begin{array}{clllll}\begin{array}{c}\text { Sem dificuldade } \\ \text { por causa }\end{array} & \begin{array}{l}\text { Um pouco de } \\ \text { dificuldade por }\end{array} & \begin{array}{c}\text { Dificuldade } \\ \text { moderada por }\end{array} & \begin{array}{c}\text { Dificuldade } \\ \text { extrema por }\end{array} & \begin{array}{c}\text { Não consegue } \\ \text { fazer por }\end{array} & \begin{array}{c}\text { Meu(inha) filho(a) muito pequeno(a) } \\ \text { da visão }\end{array} \\ \text { causa da visão } & \text { causa da visão } & \text { causa da visão } & \text { causa da visão } & \text { para tentar isso }\end{array}$

16. Meu(inha) filho(a) consegue reconhecer rostos (amigos, parentes) do outro lado da sala.

17. Meu(inha) filho(a) consegue escovar seus dentes.

18. Meu(inha) filho(a) consegue lavar seu rosto. 19. Meu(inha) filho(a) consegue seguir um móbile ou um brinquedo que se move.

20. Meu(inha) filho(a) consegue localizar um pequeno pedaço de comida (migalha de pão) e pegá-lo.

21. Meu(inha) filho(a) ajuda com os afazeres de casa (trabalhos domésticos).

Como a visão de seu(ua) filho(a) afeta as atividades dele(a)?

Por favor, indique o quanto você concorda com as sentenças abaixo:

\begin{tabular}{|c|c|c|c|c|c|c|}
\hline & $\begin{array}{l}\text { Discordo } \\
\text { plenamente }\end{array}$ & Discordo & $\begin{array}{l}\text { Não estou } \\
\text { certo }\end{array}$ & Concordo & $\begin{array}{l}\text { Concordo } \\
\text { plenamente }\end{array}$ & $\begin{array}{l}\text { Não se aplica a } \\
\text { meu(inha) filho(a) }\end{array}$ \\
\hline \multicolumn{7}{|l|}{$\begin{array}{l}\text { 23. A visão de meu(inha) filho(a) dificulta que } \\
\text { ele(a) aprenda a andar, correr, saltar ou pular. }\end{array}$} \\
\hline \multicolumn{7}{|l|}{$\begin{array}{l}\text { 24. Meu(inha) filho(a) gosta de assistir TV, } \\
\text { vídeos, ou de jogar videogames. }\end{array}$} \\
\hline \multicolumn{7}{|l|}{$\begin{array}{l}\text { 25. Meu(inha) filho(a) gosta de brincar } \\
\text { com os outros (irmãos ou amigos). }\end{array}$} \\
\hline
\end{tabular}

Nunca Raramente Às vezes Frequentemente Sempre Meu(inha) filho(a)

é muito pequeno(a) para tentar isso

27. Meu(inha) filho(a) faz contato visual comigo e sorri.

28. Meu(inha) filho(a) esbarra nas pessoas, paredes ou mobília.

29. Meu(inha) filho(a) tropeça em degraus ou no meio fio.

Perguntas sobre o tratamento da condição ocular de seu(ua) filho(a).

30. Seu(ua) filho(a) está realizando tratamento para a condição visual dele(a) [o tratamento inclui por exemplo óculos, lente de contato, lente intraocular, oclusão (tampão), colírios ou outro tipo de tratamento]?

Por favor, circule um:

$\mathrm{SIM} / \mathrm{NA \tilde {O }}$

Se responder NÃO para a questão 30 , siga para a próxima página;

Se responder SIM para a questão 30 , por favor, responda as questões a seguir:

31. Eu tenho problema para aplicar o tratamento (por exemplo,

colocar os óculos ou tampão, instilar colírio ou outra medicação).

Nunca

Raramente

Às vezes

Frequentemente

Sempre 
(Continuação) Anexo 1 - QFVI - 3 - Questionário de Função Visual Infantil (Versão para crianças menores de 3 anos)

32. Meu(inha) filho(a) fica incomodado(a) quando tratado(a) (por exemplo, quando usa óculos ou tampão ou quando recebe colírios).

33. Meu(inha) filho(a) é menos ativo(a) quando tratado(a) (por exemplo, quando usa óculos ou tampão, ou quando recebe colírios ou medicação).

34. Eu me preocupo quando meu(inha) filho(a) recusa o tratamento (por exemplo tira os óculos ou tampão,

ou fecha os olhos na hora de colocar o colírio).

35. Eu algumas vezes esqueço de tratar o(a) meu(inha) filho(a).

Perguntas sobre você (pais/responsáveis/cuidadores):

Esta informação é usada para termos certeza de que temos um grupo diverso de famílias.

O que você é da criança: ( ) Pai/Mãe $\quad(\quad)$ Responsável Legal $\quad(\quad)$ Avô/Avó $\quad(\quad)$ Outro(a)

Sexo:

( ) Masculino ( ) Feminino

Idade:

( ) Abaixo de 21

Raça:

Estado civil:

) Branco(a) ( ) Negro(a)

Você mora em:

( ) Solteiro(a)

( ) Casado(a)

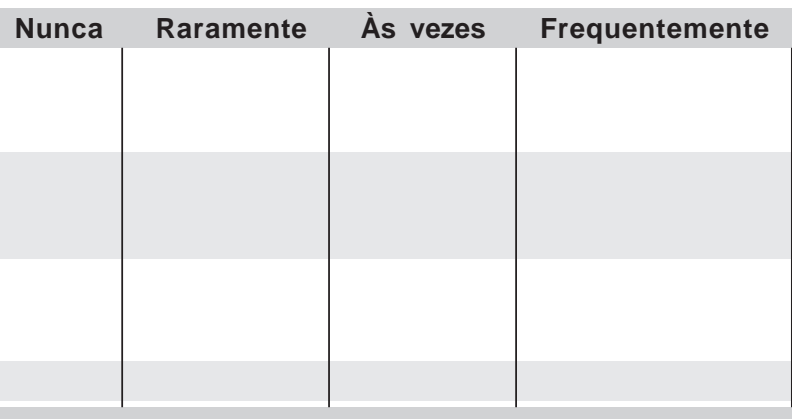

Sempre

Sua casa é:

) Cidade

) Área rural

( ) Própria

( ) Alugada

( ) 31-40

( ) Pardo(a)

( ) 41-50

( ) Separado(a)

( ) Amarelo(a)

( ) Acima de 50

Número de adultos na sua casa:

Número de crianças na sua casa:

Sua educação: $\quad$ ( ) Analfabeto(a)

( ) $2^{\circ}$ grau incompleto

( ) Superior incompleto

( ) $1^{\circ}$ grau incompleto
( ) $2^{\circ}$ grau completo
( ) Superior completo

Quem cuida de seu(ua) filho(a) durante o dia:

( ) Eu mesmo(a) ou esposa(o)

( ) Outro adulto em minha casa

( ) Escola

( ) Outro adulto na casa dele(a)

( ) Creche

Obrigada(o) por responder as perguntas!

\section{Dados Pessoais}

Idade do Paciente

Diagnóstico Oftalmológico:

Outro Diagnóstico:

Primeira Visita?

Está sob tratamento atualmente?

$\begin{array}{ll}\text { ( } & \text { ) Sim } \\ \text { ( ) Sim } \\ \text { ( ) Óculos }\end{array}$

( ) Não

( ) Não

Outro tratamento:

Acuidade OD

( ) Oclusão

( ) Colírios

( ) Cirurgia Outro:

Método usado para avaliação da acuidade

Classificação da deficiência de acuidade visual:
OD:
( ) Grave
( ) Moderada
( ) Leve
( ) Limite
( ) Normal
OE:
( ) Grave
( ) Moderada ( ) Leve
( ) Limite
( ) Normal

(Para diferenças interoculares significantes, p.ex. em pacientes amblíopes, por favor classifique o olho mais fraco relativo ao olho mais forte)

A criança tem atraso no desenvolvimento?
( ) SIM
( ) NÃO
( ) Não Sabe

Outras condições médicas significantes:

Data Rubrica 


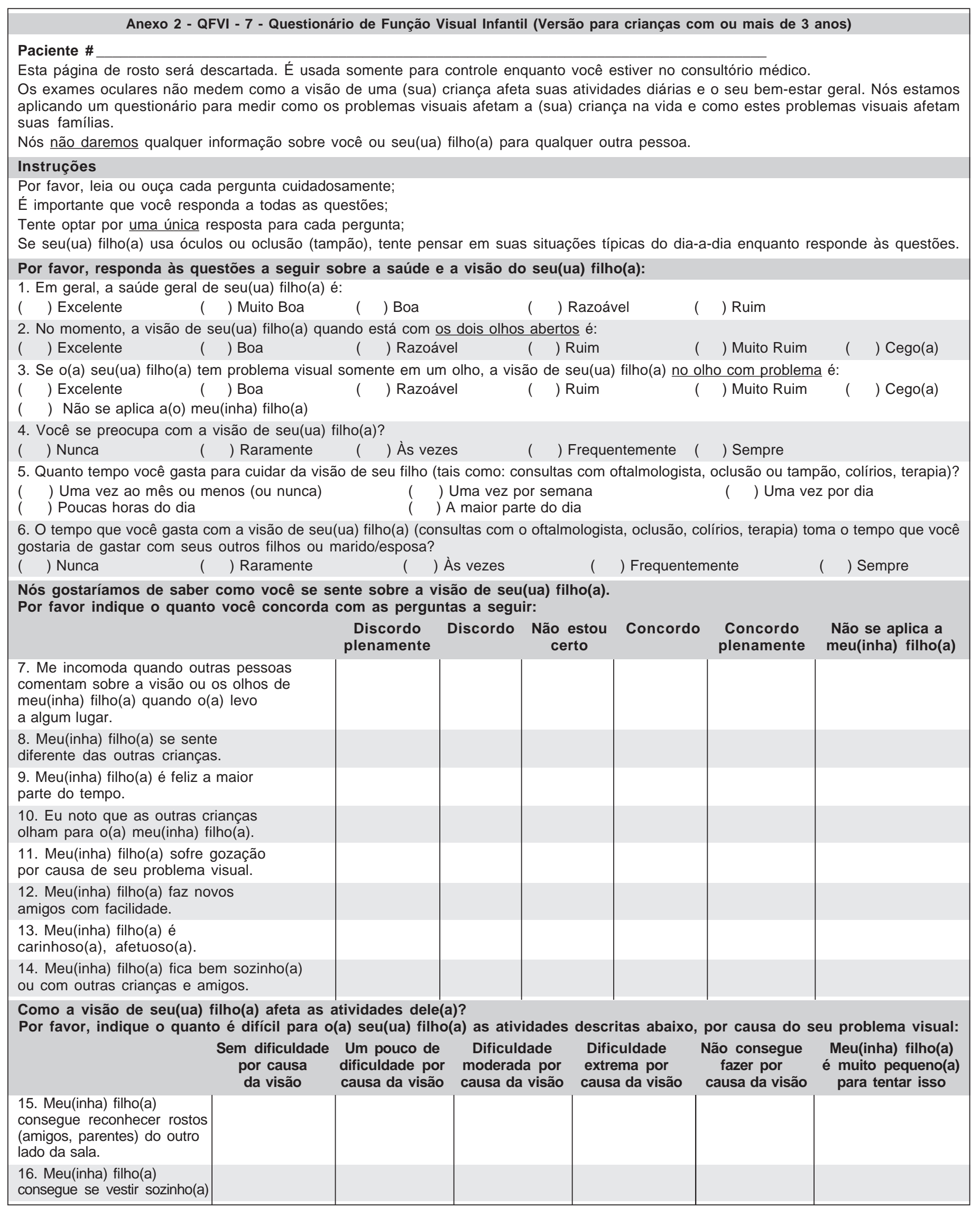


(Continuação) Anexo 2 - QFVI - 7 - Questionário de Função Visual Infantil (Versão para crianças com ou mais de 3 anos)

Como a visão de seu(a) filho(a) afeta as atividades dele(a)?

Por favor, indique o quanto são difíceis para o seu(ua) filho(a) as atividades descritas abaixo, por causa do seu problema visual:

Sem dificuldade Um pouco de Dificuldade Dificuldade por causa dificuldade por moderada por extrema por da visão causa da visão causa da visão causa da visão Não consegue fazer por Meu(inha) filho(a) causa da visão é muito pequeno(a)

17. Meu(inha) filho(a) consegue escovar seus dentes.

18. Meu(inha) filho(a) consegue lavar seu rosto.

19. Meu(inha) filho(a) consegue andar de bicicleta.

20. Meu(inha) filho(a) consegue praticar esportes ou atividades de jogos (pega-pega)

21. Meu(inha) filho(a) consegue despejar líquido num copo ou xícara.

22. Meu filho consegue discar no telefone.

23. Meu(inha) filho(a) ajuda com os afazeres de casa (trabalhos domésticos).

24. Meu(inha) filho(a) consegue falar que horas são.

25. Meu(inha) filho(a) consegue identificar moedas.

Como a visão de seu filho afeta as atividades dele?

Por favor, indique o quanto você concorda com as sentenças abaixo:

26. Meu(inha) filho(a) gosta de ver livros.

27. A visão de meu(inha) filho(a) dificulta que ele(a) aprenda a andar, correr, saltar ou pular.

28. A visão de meu(inha) filho(a) atrapalha seu aprendizado.

29. Meu(inha) filho(a) gosta de ver TV, vídeos, ou de jogar videogames.

30. Meu(inha) filho(a) gosta de viajar de férias com a família.

31. Meu(inha) filho(a) gosta de brincar com os outros (irmãos ou amigos).

32. Meu(inha) filho(a) gosta de desenhar, pintar ou de outras atividades de artes.

33. A visão de meu(inha) filho(a) dificulta que ele(a) encontre algo em uma prateleira ou em um armário.

\section{Por favor, indique com que frequência acontece:}

\section{Discordo plenamente}

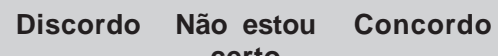
certo

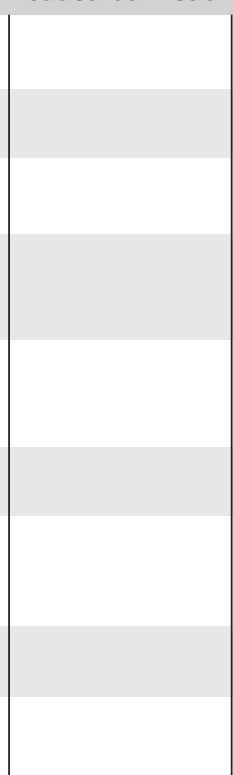
para tentar isso
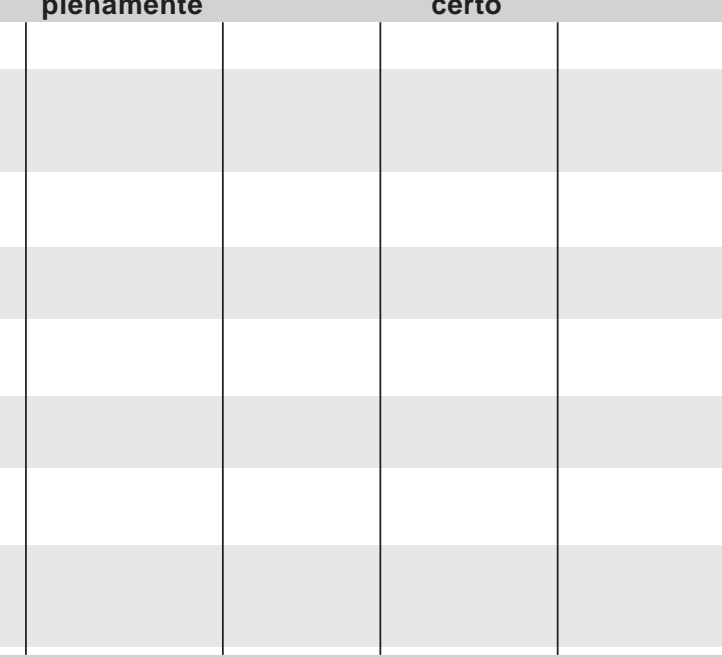

Concordo

Não se aplica a plenamente meu(inha) filho(a)

\section{Nunca Raramente Às vezes Frequentemente Sempre}

Meu(inha) filho(a) é muito pequeno(a)

34. Meu(inha) filho(a) tropeça em degraus ou no meio fio.

Perguntas sobre o tratamento da condição ocular de seu(ua) fiho(a).

para tentar isso

35. Seu filho está realizando tratamento para a condição visual dele [o tratamento inclui por exemplo óculos, lente de contato, lente intraocular, oclusão (tampão), colírios ou outro tipo de tratamento]?

$$
\begin{gathered}
\text { Por favor, circule um: } \\
\text { SIM / NÃO }
\end{gathered}
$$

Se responder NÃO para a questão 35, siga para a próxima página; 
(Continuação) Anexo 2 - QFVI - 7 - Questionário de Função Visual Infantil (Versão para crianças com ou mais de 3 anos)

Se responder SIM para a questão 35 , por favor, responda as questões a seguir:

36. Eu tenho problema para aplicar o tratamento (por exemplo, colocar os óculos ou tampão, instilar colírio ou outra medicação). 37. Meu(inha) filho(a) fica incomodado(a) quando tratado(a) (por exemplo, quando usa óculos ou tampão ou quando recebe colírios).

38. Meu(inha) filho(a) é menos ativo(a) quando tratado(a) (por exemplo, quando usa óculos ou tampão, ou quando recebe colírios ou medicação).

39. Eu me preocupo quando meu(inha) filho(a) recusa o tratamento (por exemplo tira os óculos ou tampão, ou fecha os olhos na hora de colocar o colírio).

40. Eu algumas vezes esqueço do tratamento do(a) meu(inha) filho(a).

Perguntas sobre você (pais/responsáveis/cuidadores):
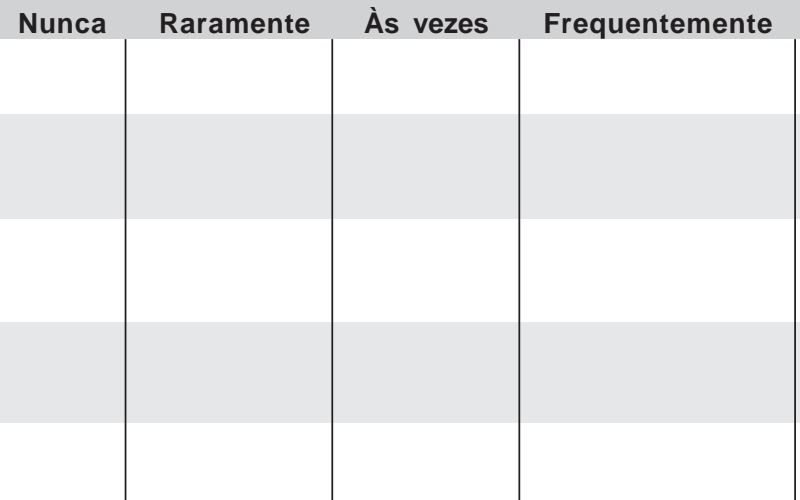

Sempre

Esta informação é usada para termos certeza de que temos um grupo diverso de famílias.

O que você é da criança: ( ) Pai/Mãe $\quad(\quad)$ Responsável Legal $\quad(\quad)$ Avô/Avó $\quad(\quad)$ Outro(a)

Sexo: $\quad($ ) Masculino $\quad(\quad)$ Feminino

Idade: ( ) Abaixo de $21 \quad(\quad)$ 21-30

Raça: ( ) Branco(a) ( ) Negro(a)

Estado civil: $\quad(\quad$ ) Solteiro(a) $\quad(\quad$ ) Casado(a)

Você mora em: $\quad(\quad)$ Cidade $\quad(\quad)$ Área rural

Sua casa é: ( ) Própria ( ) Alugada Outro

Número de adultos na sua casa:

Sua educação: $\quad($ ) Analfabeto(a)

( ) $2^{\circ}$ grau incompleto

( ) Superior incompleto

Número de crianças na sua casa:

Quem cuida de seu(ua) filho(a) durante o dia:

( ) Eu mesmo(a) ou esposa(o)

( ) Creche

Obrigada(o) por responder as perguntas!
( ) Outro adulto em minha casa

( ) Escola
( ) $1^{\circ}$ grau incompleto

( ) $2^{\circ}$ grau completo

( ) Superior completo
( ) 1 grau completo

( ) Pós-graduação
) Acima de 50

( ) Amarelo(a) ( ) Índio(a)

( ) Divorciado(a) ( ) Viúvo(a)

\section{Dados Pessoais}

Idade do Paciente

Diagnóstico Oftalmológico:

Outro Diagnóstico:

Primeira Visita?

Está sob tratamento atualmente?

$(\quad) \operatorname{Sim} \quad(\quad)$ Não

( ) Sim ( ) Não

( ) Óculos ( ) Oclusão ( ) Colírios ( ) Cirurgia

Outro tratamento:

Acuidade OD Acuidade OE

Método usado para avaliação da acuidade

Classificação da deficiência de acuidade visual:
OD:
OE:
( ) Grave
( ) Grave
( ) Moderada
( ) Leve
( ) Limite
( ) Normal
( ) Moderada
( ) Leve
( ) Limite
( ) Normal

(Para diferenças interoculares significantes, p.ex. em pacientes amblíopes, por favor classifique o olho mais fraco relativo ao olho mais forte) A criança tem atraso no desenvolvimento?
( ) SIM
( ) NÃO
( ) Não Sabe

Outras condições médicas significantes: 


\begin{tabular}{|lcc|}
\hline $\begin{array}{l}\text { Tabela 1. Descrição da distribuição de sexo e idade, com média } \\
\text { e desvio padrão, das crianças participantes }\end{array}$ \\
$\begin{array}{lcc}\text { Grupo experimental } & <3 \text { anos } & \mathbf{3} \text { a } 7 \text { anos } \\
\text { Sexo } & & \\
\text { Masculino } & 13 & 8 \\
\text { Feminino } & 6 & 10 \\
\text { Total } & 19 & 18 \\
\text { Idade } & 4 \text { a } 34 \text { meses } & 3 \text { a } 7 \text { anos } \\
& 14,6 \text { meses } & 4,4 \text { anos } \\
\text { (dp }=1,5)\end{array}$ \\
\hline Grupo controle & $(\mathrm{dp}=10,7)$ & 3 a 7 anos \\
Sexo & $<3$ anos & 3 \\
Masculino & 7 & 12 \\
Feminino & 10 & 15 \\
Total & 17 & 3 a 7 anos \\
Idade & 2 a 35 meses & 4,2 anos \\
& 26,9 meses & (dp $=1,3)$ \\
\hline
\end{tabular}

\begin{tabular}{|c|c|}
\hline \multicolumn{2}{|c|}{ Grupo sem deficiência visual } \\
\hline \multicolumn{2}{|c|}{ Sexo } \\
\hline Masculino & 7 \\
\hline Feminino & 9 \\
\hline Total & 16 \\
\hline Idade & 34,1 meses $(d p=26,2)$ \\
\hline$<3$ anos & 7 \\
\hline 3 a 7 anos & 9 \\
\hline \multicolumn{2}{|c|}{ Grupo com deficiência visual leve } \\
\hline \multicolumn{2}{|c|}{ Sexo } \\
\hline Masculino & 6 \\
\hline Feminino & 4 \\
\hline Total & 10 \\
\hline Idade & 39 meses $(\mathrm{dp}=26,8)$ \\
\hline$<3$ anos & 6 \\
\hline 3 a 7 anos & 4 \\
\hline \multicolumn{2}{|c|}{ Grupo com deficiência visual grave } \\
\hline \multicolumn{2}{|c|}{ Sexo } \\
\hline Masculino & 3 \\
\hline Feminino & 8 \\
\hline Total & 11 \\
\hline Idade & 27,5 meses $(d p=19,3)$ \\
\hline$<3$ anos & 6 \\
\hline 3 a 7 anos & 5 \\
\hline
\end{tabular}

déficit em sua qualidade de vida geral relacionada à visão, sendo a maior perda encontrada no domínio de impacto da família perante a deficiência, seguida pela competência na realização das atividades. Nos grupos alocados segundo a gravidade da deficiência visual, o que apresentou a pior nota, por obter baixa nota composta total e, portanto o maior comprometimento da qualidade de vida relacionada à visão foi o grupo composto por crianças com deficiência visual grave.
As crianças do grupo controle apresentaram todas as notas dos domínios acima de 90 , com baixo desvio padrão, mostrando a validade do QFVI.

Pesquisa realizada em crianças com catarata congênita bilateral em instituição americana, mostrou ausência na diferença entre grupos etários, menor e maior de 3 anos, o que se confirmou no presente estudo ${ }^{(13)}$. No mesmo levantamento, no entanto, em crianças com retinopatia da prematuridade, a pior nota quanto à qualidade de vida foi observada nas crianças com maior gravidade do comprometimento visual.

Dados semelhantes aos encontrados nesta pesquisa foram descritos em estudo realizado na Alemanha, onde, levantadas informações entre o desempenho de crianças com ambliopia, em tratamento com oclusão e uso de lentes de contato em afácicos, a nota composta total dos grupos (amblíope e afácicos) apresentaram baixa nota na qualidade de vida e estatisticamente inferior se comparados às crianças de visão normal ${ }^{(14)}$. Quanto às subescalas, as diferenças estatisticamente significativas foram observadas em competência e impacto familiar, isso se comparado ao grupo controle ${ }^{(14)}$.

Em contrapartida, no presente estudo, as diferenças estatisticamente significativas foram observadas em todas as subescalas. Cabe ressaltar que ao se comparar os grupos segundo a gravidade do comprometimento visual, o grupo de crianças com perda visual grave se mostrou com baixa nota na subescala competência.

O QFVI é um importante instrumento válido para mensurar o impacto da deficiência visual em crianças e em seus familiares, mostrando que a qualidade de vida relacionada à visão está reduzida em crianças com catarata congênita bilateral e pode direcionar tratamentos e condutas terapêuticas e de reabilitação.

\section{CONCLUSÃO}

A qualidade de vida relacionada à visão em crianças com catarata congênita bilateral, avaliada pelo QFVI mostraram que: os grupos de crianças com catarata congênita bilateral, menores e maiores de 3 anos, apresentaram maior comprometimento nos domínios de impacto familiar, seguido por competência; o grupo de crianças com catarata congênita bilateral, maiores de 3 anos, apresentou maior comprometimento nos domínios de impacto familiar, seguido por competência; em crianças com catarata congênita bilateral e deficiência visual grave e com catarata congênita bilateral sem deficiência visual, o domínio tratamento foi o de valor mais baixo; nas crianças com catarata congênita bilateral com deficiência visual leve, o domínio impacto familiar foi o de valor mais baixo; na comparação das crianças com catarata congênita bilateral com o grupo controle, a competência foi o domínio estatisticamente com o menor valor.

\section{AGRADECIMENTOS}

Bolsa CAPES - Coordenação de Aperfeiçoamento de Pessoal de Nível Superior do Ministério da Educação - Governo Federal. 


\begin{tabular}{|c|c|c|c|c|c|}
\hline & & Grupo I & Grupo II & Grupo Ic & Grupo IIc \\
\hline \multirow[t]{3}{*}{ Parentesco } & Pais & 17 & 12 & 10 & 13 \\
\hline & Avós & 2 & 3 & 4 & 2 \\
\hline & Outros & 0 & 2 & 1 & 2 \\
\hline \multirow[t]{2}{*}{ Sexo } & Feminino & 16 & 16 & 12 & 16 \\
\hline & Masculino & 3 & 1 & 3 & 1 \\
\hline \multirow[t]{5}{*}{ Idade } & Abaixo 21 anos & 4 & 2 & 0 & 0 \\
\hline & 21 a 30 anos & 5 & 7 & 4 & 7 \\
\hline & 31 a 40 anos & 7 & 5 & 10 & 7 \\
\hline & 41 a 50 anos & 1 & 0 & 0 & 2 \\
\hline & Acima 50 anos & 2 & 3 & 1 & 1 \\
\hline \multirow[t]{3}{*}{ Estado civil } & Casado & 15 & 13 & 10 & 12 \\
\hline & Solteiro & 2 & 2 & 4 & 4 \\
\hline & Divorciado / Viúvo & 2 & 2 & 1 & 1 \\
\hline \multirow[t]{5}{*}{ Residência } & Cidade & 16 & 17 & 15 & 10 \\
\hline & Rural & 3 & 0 & 0 & 7 \\
\hline & Própria & 14 & 17 & 11 & 10 \\
\hline & Alugadas & 2 & 0 & 4 & 4 \\
\hline & Outras & 3 & 0 & 0 & 3 \\
\hline \multirow[t]{2}{*}{ № pessoas } & Adultos & 3 & 2 & 2 & 2 \\
\hline & Crianças & 2 & 1 & 2 & 3 \\
\hline \multirow[t]{7}{*}{ Escolaridade } & $1^{\circ}$ completo & 6 & 1 & 3 & 2 \\
\hline & 1 incompleto & 0 & 0 & 0 & 2 \\
\hline & $2^{\circ}$ completo & 9 & 6 & 5 & 6 \\
\hline & $2^{\circ}$ incompleto & 0 & 0 & 0 & 2 \\
\hline & Superior & 3 & 7 & 4 & 2 \\
\hline & Pós-graduação & 1 & 3 & 0 & 0 \\
\hline & Não letrados & 0 & 0 & 3 & 3 \\
\hline \multirow[t]{3}{*}{ Cuidadores } & Respondente & 14 & 14 & 9 & 9 \\
\hline & Outro & 4 & 3 & 5 & 4 \\
\hline & Creche / Escola & 3 & 9 & 13 & 4 \\
\hline
\end{tabular}

\begin{tabular}{|c|c|c|c|c|c|c|c|c|c|}
\hline \multirow{3}{*}{ Domínio } & \multicolumn{8}{|c|}{ Questões e respostas } & \multirow{3}{*}{ Explicação das questões } \\
\hline & \multirow[t]{2}{*}{ Questão } & \multicolumn{7}{|c|}{ Alternativas de resposta } & \\
\hline & & $1^{\circ}$ & $2^{\circ}$ & $3^{\circ}$ & $4^{\circ}$ & $5^{\circ}$ & $6^{\circ}$ & $7^{\circ}$ & \\
\hline Saúde geral & 1 & 100 & 75 & 50 & 25 & 0 & & & Em geral a saúde do(a) seu(ua) filho(a)...? \\
\hline \multirow[t]{2}{*}{ Saúde geral da visão } & 2 & 100 & 80 & 60 & 40 & 20 & 0 & & $\begin{array}{l}\text { Neste momento, a visão do(a) seu(ua) } \\
\text { filho(a) com o uso dos dois olhos...? }\end{array}$ \\
\hline & 3 & 100 & 80 & 60 & 40 & 20 & 0 & não se aplica & $\begin{array}{l}\text { Se o problema da visão do(a) } \\
\text { seu(ua) filho(a) é somente em um } \\
\text { dos olhos, no olho com problema...? }\end{array}$ \\
\hline \multirow[t]{9}{*}{ Competência } & 13 & 100 & 75 & 50 & 25 & 0 & não se aplica & & $\begin{array}{l}\text { Preocupo-me se meu(inha) filho(a) não será capaz } \\
\text { de ler, assistir televisão ou dirigir um carro }\end{array}$ \\
\hline & 15 & 100 & 75 & 50 & 25 & 0 & não se aplica & & $\begin{array}{l}\text { Meu(inha) filho(a) consegue } \\
\text { se alimentar sozinho(a) }\end{array}$ \\
\hline & 16 & 100 & 75 & 50 & 25 & 0 & não se aplica & & $\begin{array}{l}\text { Meu(inha) filho(a) consegue reconhecer rostos } \\
\text { (amigos, parentes) do outro lado de um quarto }\end{array}$ \\
\hline & 17 & 100 & 75 & 50 & 25 & 0 & não se aplica & & $\begin{array}{l}\text { Meu(inha) filho(a) consegue } \\
\text { escovar seus dentes }\end{array}$ \\
\hline & 18 & 100 & 75 & 50 & 25 & 0 & não se aplica & & $\begin{array}{l}\text { Meu(inha) filho(a) consegue } \\
\text { lavar seu rosto }\end{array}$ \\
\hline & 19 & 100 & 75 & 50 & 25 & 0 & não se aplica & & $\begin{array}{l}\text { Meu(inha) filho(a) segue móbiles } \\
\text { ou brinquedos em movimento }\end{array}$ \\
\hline & 20 & 100 & 75 & 50 & 25 & 0 & nãose aplica & & $\begin{array}{l}\text { Meu(inha) filho(a) consegue } \\
\text { localizar uma migalha e pegá-la }\end{array}$ \\
\hline & 21 & 100 & 75 & 50 & 25 & 0 & não se aplica & & Meu(inha) filho(a) ajuda com as tarefas \\
\hline & 23 & 100 & 75 & 50 & 25 & 0 & não se aplica & & $\begin{array}{l}\text { A visão do(a) meu(inha) filho(a) atrapalha } \\
\text { para caminhar, correr ou pular }\end{array}$ \\
\hline
\end{tabular}




\begin{tabular}{|c|c|c|c|c|c|c|c|c|c|}
\hline \multirow{4}{*}{$\begin{array}{l}\text { (Continuação) } \\
\text { Domínio }\end{array}$} & \multicolumn{9}{|c|}{ Quadro 1 A. Descrição dos valores correspondentes às notas em cada questão por domínio do QFVI - 3} \\
\hline & \multicolumn{9}{|c|}{ Questões e respostas } \\
\hline & \multirow[t]{2}{*}{ Questão } & \multicolumn{7}{|c|}{ Alternativas de resposta } & \multirow[t]{2}{*}{ Explicação das questões } \\
\hline & & $1^{\circ}$ & 20 & $3^{\circ}$ & $4^{\circ}$ & $5^{\circ}$ & 6은 & $7^{\circ}$ & \\
\hline \multirow[t]{4}{*}{ Competência } & 26 & 100 & 75 & 50 & 25 & 0 & não se aplica & & $\begin{array}{l}\text { A visão do(a) meu(inha) filho(a) atrapalha } \\
\text { para encontrar algo sobre mesas ou prateleiras }\end{array}$ \\
\hline & 27 & 0 & 25 & 50 & 75 & 100 & nãose aplica & & Meu(inha) filho(a) faz contato visual e sorri \\
\hline & 28 & 100 & 75 & 50 & 25 & 0 & não se aplica & & $\begin{array}{l}\text { Meu(inha) filho(a) esbarra em pessoas, } \\
\text { paredes ou móveis }\end{array}$ \\
\hline & 29 & 100 & 75 & 50 & 25 & 0 & não se aplica & & $\begin{array}{l}\text { Meu(inha) filho(a) tropeça em } \\
\text { degraus e meio fio }\end{array}$ \\
\hline \multirow[t]{5}{*}{ Personalidade } & 11 & 0 & 25 & 50 & 75 & 100 & não se aplica & & Meu(inha) filho(a) gosta de visitar seus parentes \\
\hline & 14 & 0 & 25 & 50 & 75 & 100 & nãose aplica & & $\begin{array}{l}\text { Meu(inha) filho(a) fica bem com } \\
\text { outras crianças e amigos }\end{array}$ \\
\hline & 22 & 0 & 25 & 50 & 75 & 100 & nãose aplica & & Meu(inha) filho(a) gosta de ler livros \\
\hline & 24 & 0 & 25 & 50 & 75 & 100 & não se aplica & & $\begin{array}{l}\text { Meu(inha) filho(a) gosta de } \\
\text { assistir TV e jogar videogames }\end{array}$ \\
\hline & 25 & 0 & 25 & 50 & 75 & 100 & não se aplica & & $\begin{array}{l}\text { Meu(inha) filho(a) gosta de brincar com } \\
\text { outras pessoas (irmãos e amigos) }\end{array}$ \\
\hline \multirow[t]{8}{*}{ Impacto familiar } & 4 & 100 & 75 & 50 & 25 & 0 & & & $\begin{array}{l}\text { Você se preocupa com a visão } \\
\text { do(a) seu(ua) filho(a)? }\end{array}$ \\
\hline & 5 & 100 & 75 & 50 & 25 & 0 & & & $\begin{array}{l}\text { Quanto tempo você gasta para cuidados com a visão } \\
\text { do(a) seu(ua) filho(a)? (consultas, colírios, terapias) }\end{array}$ \\
\hline & 6 & 100 & 75 & 50 & 25 & 0 & & & $\begin{array}{l}\text { Com o tempo que você gasta para os cuidados } \\
\text { da visão do(a) seu(ua) filho(a), poderia gastar } \\
\text { com seus outros filhos ou marido? }\end{array}$ \\
\hline & 7 & 100 & 75 & 50 & 25 & 0 & & & $\begin{array}{l}\text { Você e os outros membros da família } \\
\text { conversam sobre os cuidados com seu(ua) } \\
\text { filho(a) e tratamentos prescritos? }\end{array}$ \\
\hline & 8 & 100 & 75 & 50 & 25 & 0 & & & $\begin{array}{l}\text { Incomoda-me quando outras pessoas comentam } \\
\text { sobre o problema visual do(a) meu(inha) filho(a), } \\
\text { quando vou à farmácia ou ao mercado }\end{array}$ \\
\hline & 9 & 100 & 75 & 50 & 25 & 0 & não se aplica & & $\begin{array}{l}\text { Meu(inha) filho(a) sente-se diferente } \\
\text { das outras crianças }\end{array}$ \\
\hline & 10 & 100 & 75 & 50 & 25 & 0 & não se aplica & & $\begin{array}{l}\text { Percebo que outras crianças } \\
\text { olham para meu(inha) filho(a) }\end{array}$ \\
\hline & 12 & 100 & 75 & 50 & 25 & 0 & não se aplica & & $\begin{array}{l}\text { Meu(inha) filho(a) irrita-se por causa } \\
\text { do problema de visão }\end{array}$ \\
\hline \multirow[t]{5}{*}{ Tratamento } & 31 & 100 & 75 & 50 & 25 & 0 & & & $\begin{array}{l}\text { Tenho problema para aplicar o tratamento } \\
\text { (por exemplo, colocar a oclusão, colocar colírio } \\
\text { ou outro medicamento) }\end{array}$ \\
\hline & 32 & 100 & 75 & 50 & 25 & 0 & & & $\begin{array}{l}\text { Meu(inha) filho(a) fica incomodado(a) quando } \\
\text { é tratado (por exemplo, colocar os óculos } \\
\text { ou oclusão e colocar colírio) }\end{array}$ \\
\hline & 33 & 100 & 75 & 50 & 25 & 0 & & & $\begin{array}{l}\text { Meu(inha) filho(a) fica menos ativo(a) quando } \\
\text { é tratado(a) (por exemplo, colocar os óculos } \\
\text { ou oclusão e colocar colírio) }\end{array}$ \\
\hline & 34 & 100 & 75 & 50 & 25 & 0 & & & $\begin{array}{l}\text { Fico preocupado(a) quando meu(inha) filho(a) } \\
\text { recusa o tratamento (por exemplo, colocar os } \\
\text { óculos ou oclusão e colocar colírio) }\end{array}$ \\
\hline & 35 & 100 & 75 & 50 & 25 & 0 & & & $\begin{array}{l}\text { Algumas vezes esqueço de fazer o tratamento } \\
\text { do(a) meu(inha) filho(a) }\end{array}$ \\
\hline
\end{tabular}

\section{ABSTRACT}

Purpose: To assess vision-related quality of life in children with bilateral congenital cataracts, using the recently deve- loped Children's Visual Function Questionnaire (CVFQ). Methods: CVFQ has two presentations, one for children under 3 years of age and the other for older children, and is divided in six subscales - general health; general vision; competence; 


\begin{tabular}{|c|c|c|c|c|c|c|c|c|c|}
\hline \multicolumn{10}{|c|}{ Quadro 1 B. Descrição dos valores correspondentes às notas em cada questão por domínio do QFVI - 7} \\
\hline \multirow{3}{*}{ Domínio } & \multicolumn{8}{|c|}{ Questões e respostas } & \multirow{3}{*}{ Explicação das questões } \\
\hline & \multirow[t]{2}{*}{ Questão } & \multicolumn{7}{|c|}{ Alternativas de resposta } & \\
\hline & & $1^{\circ}$ 은 & $2^{\circ}$ & 3은 & $4^{\circ}$ & $5^{\circ}$ & $6^{\circ}$ & $7^{\circ}$ & \\
\hline Saúde geral & 1 & 100 & 75 & 50 & 25 & 0 & & & Em geral a saúde do(a) seu(ua) filho(a)...? \\
\hline \multirow[t]{2}{*}{ Saúde geral da visão } & 2 & 100 & 80 & 60 & 40 & 20 & 0 & & $\begin{array}{l}\text { Neste momento, a visão do(a) seu(ua) } \\
\text { filho(a) com o uso dos dois olhos...? }\end{array}$ \\
\hline & 3 & 100 & 80 & 60 & 40 & 20 & 0 & não se aplica & $\begin{array}{l}\text { Se o problema da visão do(a) seu(ua) filho(a) é } \\
\text { somente em um dos olhos, no olho afetado...? }\end{array}$ \\
\hline \multirow[t]{15}{*}{ Competência } & 15 & 100 & 75 & 50 & 25 & 0 & não se aplica & & $\begin{array}{l}\text { Meu(inha) filho(a) consegue reconhecer rostos } \\
\text { (amigos, parentes) do outro lado de um quarto }\end{array}$ \\
\hline & 16 & 100 & 75 & 50 & 25 & 0 & não se aplica & & $\begin{array}{l}\text { Meu(inha) filho(a) consegue } \\
\text { se vestir sozinho(a) }\end{array}$ \\
\hline & 17 & 100 & 75 & 50 & 25 & 0 & não se aplica & & $\begin{array}{l}\text { Meu(inha) filho(a) consegue } \\
\text { escovar seus dentes }\end{array}$ \\
\hline & 18 & 100 & 75 & 50 & 25 & 0 & não se aplica & & $\begin{array}{l}\text { Meu(inha) filho(a) consegue } \\
\text { lavar seu rosto }\end{array}$ \\
\hline & 19 & 100 & 75 & 50 & 25 & 0 & não se aplica & & $\begin{array}{l}\text { Meu(inha) filho(a) consegue } \\
\text { andar de bicicleta }\end{array}$ \\
\hline & 20 & 100 & 75 & 50 & 25 & 0 & não se aplica & & $\begin{array}{l}\text { Meu(inha) filho(a) consegue } \\
\text { brincar de pega-pega e esconde-esconde }\end{array}$ \\
\hline & 21 & 100 & 75 & 50 & 25 & 0 & não se aplica & & $\begin{array}{l}\text { Meu(inha) filho(a) consegue } \\
\text { despejar líquido em um copo }\end{array}$ \\
\hline & 22 & 100 & 75 & 50 & 25 & 0 & não se aplica & & Meu(inha) filho(a) consegue discar o telefone \\
\hline & 23 & 100 & 75 & 50 & 25 & 0 & não se aplica & & Meu(inha) filho(a) ajuda nas tarefas \\
\hline & 24 & 100 & 75 & 50 & 25 & 0 & não se aplica & & Meu(inha) filho(a) consegue ver que horas são \\
\hline & 25 & 100 & 75 & 50 & 25 & 0 & não se aplica & & Meu(inha) filho(a) consegue identificar moedas \\
\hline & 27 & 100 & 75 & 50 & 25 & 0 & nãose aplica & & $\begin{array}{l}\text { A visão do(a) meu(inha) filho(a) } \\
\text { atrapalha para caminhar, correr ou pular }\end{array}$ \\
\hline & 28 & 100 & 75 & 50 & 25 & 0 & não se aplica & & $\begin{array}{l}\text { A visão do(a) meu(inha) filho(a) } \\
\text { atrapalha o aprendizado }\end{array}$ \\
\hline & 33 & 100 & 75 & 50 & 25 & 0 & não se aplica & & $\begin{array}{l}\text { A visão do(a) meu(inha) filho(a) atrapalha para } \\
\text { encontrar algo sobre mesas ou prateleiras }\end{array}$ \\
\hline & 34 & 100 & 75 & 50 & 25 & 0 & não se aplica & & Meu(inha) filho(a) tropeça em degraus e meio fio \\
\hline \multirow[t]{9}{*}{ Personalidade } & 9 & 0 & 25 & 50 & 75 & 100 & não se aplica & & $\begin{array}{l}\text { Meu(inha) filho(a) é alegre na maior } \\
\text { parte do tempo }\end{array}$ \\
\hline & 12 & 0 & 25 & 50 & 75 & 100 & não se aplica & & Meu(inha) filho(a) faz amizade com facilidade \\
\hline & 13 & 0 & 25 & 50 & 75 & 100 & não se aplica & & Meu(inha) filho(a) é afetuoso(a) \\
\hline & 14 & 0 & 25 & 50 & 75 & 100 & não se aplica & & $\begin{array}{l}\text { Meu(inha) filho(a) fica bem com } \\
\text { outras crianças e amigos }\end{array}$ \\
\hline & 26 & 0 & 25 & 50 & 75 & 100 & não se aplica & & Meu(inha) filho(a) gosta de ler livros \\
\hline & 29 & 0 & 25 & 50 & 75 & 100 & não se aplica & & $\begin{array}{l}\text { Meu(inha) filho(a) gosta de } \\
\text { assistir TV e jogar videogames }\end{array}$ \\
\hline & 30 & 0 & 25 & 50 & 75 & 100 & não se aplica & & $\begin{array}{l}\text { Meu(inha) filho(a) gosta de viajar } \\
\text { de férias com a família }\end{array}$ \\
\hline & 31 & 0 & 25 & 50 & 75 & 100 & não se aplica & & $\begin{array}{l}\text { Meu(inha) filho(a) gosta de brincar } \\
\text { com outras pessoas (irmãos e amigos) }\end{array}$ \\
\hline & 32 & 0 & 25 & 50 & 75 & 100 & não se aplica & & Meu(inha) filho(a) gosta de pintar e desenhar \\
\hline \multirow[t]{3}{*}{ Impacto familiar } & 4 & 100 & 75 & 50 & 25 & 0 & & & $\begin{array}{l}\text { Você se preocupa com a visão } \\
\text { do(a) seu(ua) filho(a)? }\end{array}$ \\
\hline & 5 & 100 & 75 & 50 & 25 & 0 & & & $\begin{array}{l}\text { Quanto tempo você gasta para cuidados } \\
\text { com a visão do(a) seu(ua) filho(a)? } \\
\text { (consultas, colírios, terapias) }\end{array}$ \\
\hline & 6 & 100 & 75 & 50 & 25 & 0 & & & $\begin{array}{l}\text { Com o tempo que você gasta para os cuidados } \\
\text { da visão do(a) seu(ua) filho(a), poderia gastar } \\
\text { com seus outros filhos ou marido? }\end{array}$ \\
\hline
\end{tabular}




\begin{tabular}{|c|c|c|c|c|c|c|c|c|c|}
\hline \multirow[t]{2}{*}{ (Continuação) } & \multicolumn{9}{|c|}{ Quadro 1 B. Descrição dos valores correspondentes às notas em cada questão por domínio do QFVI - 3} \\
\hline & \multicolumn{9}{|c|}{ Questões e respostas } \\
\hline \multirow[t]{2}{*}{ Domínio } & \multirow[t]{2}{*}{ Questão } & \multicolumn{7}{|c|}{ Alternativas de resposta } & \multirow[t]{2}{*}{ Explicação das questões } \\
\hline & & $11^{\circ}$ & $2^{\circ}$ & 3은 & $4^{\circ}$ & $5^{\circ}$ & $6^{\circ}$ & $7^{\circ}$ & \\
\hline \multirow[t]{4}{*}{ Impacto familiar } & 7 & 100 & 75 & 50 & 25 & 0 & & & $\begin{array}{l}\text { Incomoda-me quando outras pessoas } \\
\text { comentam sobre o problema visual do(a) } \\
\text { meu(inha) filho(a), quando o(a) levo a algum lugar }\end{array}$ \\
\hline & 8 & 100 & 75 & 50 & 25 & 0 & não se aplica & & $\begin{array}{l}\text { Meu(inha) filho(a) sente-se } \\
\text { diferente das outras crianças }\end{array}$ \\
\hline & 10 & 100 & 75 & 50 & 25 & 0 & não se aplica & & $\begin{array}{l}\text { Percebo que outras crianças } \\
\text { olham para meu(inha) filho(a) }\end{array}$ \\
\hline & 11 & 100 & 75 & 50 & 25 & 0 & não se aplica & & $\begin{array}{l}\text { Meu(inha) filho(a) irrita-se por causa } \\
\text { do problema de visão }\end{array}$ \\
\hline \multirow[t]{5}{*}{ Tratamento } & 36 & 100 & 75 & 50 & 25 & 0 & & & $\begin{array}{l}\text { Tenho problema para aplicar o tratamento } \\
\text { (por exemplo, colocar a oclusão, colocar colírio } \\
\text { ou outro medicamento) }\end{array}$ \\
\hline & 37 & 100 & 75 & 50 & 25 & 0 & & & $\begin{array}{l}\text { Meu(inha) filho(a) fica incomodado(a) quando é } \\
\text { tratado(a) (por exemplo, colocar os óculos } \\
\text { ou oclusão e colocar colírio) }\end{array}$ \\
\hline & 38 & 100 & 75 & 50 & 25 & 0 & & & $\begin{array}{l}\text { Meu(inha) filho(a) fica menos ativo(a) quando é } \\
\text { tratado(a) (por exemplo, colocar os óculos } \\
\text { ou oclusão e colocar colírio) }\end{array}$ \\
\hline & 39 & 100 & 75 & 50 & 25 & 0 & & & $\begin{array}{l}\text { Fico preocupado(a) quando meu(inha) filho(a) } \\
\text { recusa o tratamento (por exemplo, colocar } \\
\text { os óculos ou oclusão e colocar colírio) }\end{array}$ \\
\hline & 40 & 100 & 75 & 50 & 25 & 0 & & & $\begin{array}{l}\text { Algumas vezes esqueço de fazer o } \\
\text { tratamento do(a) meu(inha) filho(a) }\end{array}$ \\
\hline
\end{tabular}

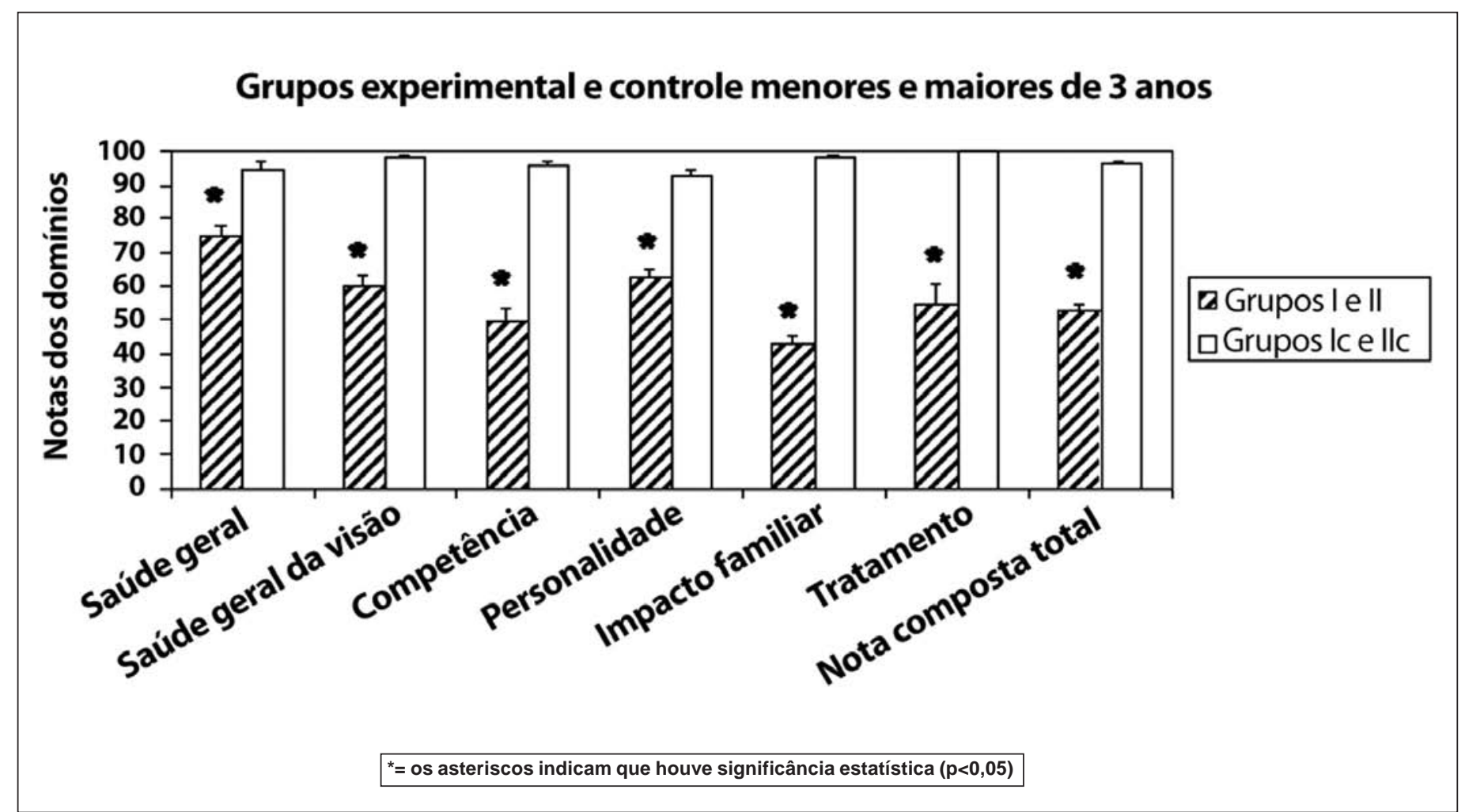

Figura 1 - Distribuição do valor médio e respectivo erro padrão da média, das notas obtidas nos diferentes domínios entre os grupos, experimental e controle (grupo I e II X grupo Ic e IIc) do QFVI 


\section{Grupos experimental - deficiência da acuidade visual}

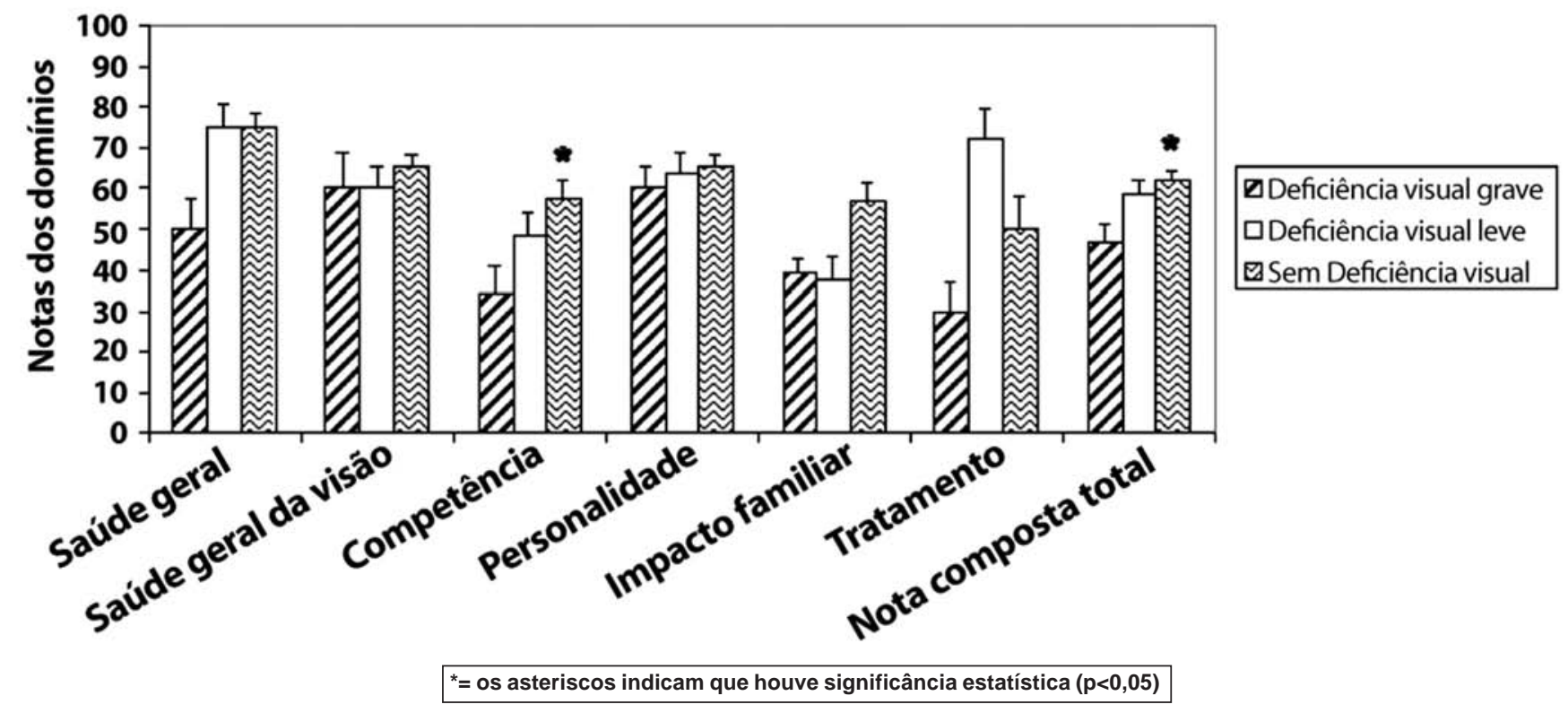

Figura 2 - Distribuição do valor médio e respectivo erro padrão da média, das notas obtidas nos diferentes domínios entre os grupos sem deficiência visual, com deficiência visual leve e com deficiência visual grave do QFVI

personality; family impact and treatment. From those, a composite score can also be calculated. The CVFQ was applied in the hospital setting to parents or other caretakers by personal interview. The subscale scores were compared for control group $(\mathrm{n}=32$ - normal vision $)$ versus congenital cataract group $(\mathrm{n}=16$ no visual impairment, $n=10$ - mild visual impairment and $n=11$ severe visual impairment). For analysis, t-tests and analysis of variance (ANOVA) were performed. Results: All quality of life subscales presented low scores for children with bilateral congenital cataracts. Congenital bilateral cataract scores were lower than those of the control group for all subscales. Competence subscale in the experimental group was significantly lower in the comparison with visual impairment severity $(\mathrm{F}=5.1$, $\mathrm{p}=0.01$; Tukey test $\mathrm{p}<0.01$ ) as well as the composite score $(\mathrm{F}=5.4, \mathrm{p}=0.01$; Tukey test $\mathrm{p}=0.01 / 0.05)$. Conclusions: Bilateral congenital cataracts influence vision-related quality of life of children as confirmed by low scores in all subscales assessed by the CVFQ with emphasis on the competence subscale. This instrument should be incorporated in the clinical assessment of children with bilateral cataracts as a measure of the impact of visual impairment in their quality of life.

Keywords: Quality of life; Cataract/congenital; Questionnaires; Vision; Low vision; Child; Caregivers

\section{REFERÊNCIAS}

1. Stelmack J. Quality of life of low-vision patients and outcomes of low-vision rehabilitation. Optom Vis Sci. 2001;78(5):335-42.
2. Chak M, Rahi JS; British Congenital Cataract Interest Group. The healthrelated quality of life of children with congenital cataract: findings of the British Congenital Cataract Study. Br J Ophthalmol. 2007;91(7):922-6.

3. Graziano RM, Leone CR. Problemas oftalmológicos mais frequentes e desenvolvimento visual do pré-termo extremo. J Pediatr (Rio J). 2005;81(1 Supl): S95-100.

4. Yorston D. Surgery for congenital cataract. Community Eye Health. 2004; 17(50):23-5.

5. Cruz CB, Endriss D, Ventura B, Ventura L. Catarata na infância: perfil socioeconômico, gestacional e desenvolvimento neuropsicomotor. Arq Bras Oftalmol. 2005;68(1):9-13.

6. Preisler G. Social and emotional development of blind children: a longitudinal study. In: Lewis V, Collins GM, organizers. Blindness and psychological development in young children. Londres: The British Psychological Society; 1997. p.69-85.

7. Wolffsohn JS, Cochrane AL. Design of the low vision quality-of-life questionnaire (LVQOL) and measuring the outcome of low-vision rehabilitation. Am J Ophalmol. 2000;130(6):793-802.

8. Childhood cataract: magnitude, management, economics and impact. Community Eye Health. 2004;17(50):17-8.

9. Boulton M, Haines L, Smyth D, Fielder A. Health-related quality of life of children with vision impairment or blindness. Dev Med Child Neurol. 2006; 48(8):656-61.

10. Muhit MA. Childhood cataract: home to hospital. Community Eye Health. 2004;17(50):19-22.

11. Felius J, Stager DR Sr, Berry PM, Fawcett SL, Stager DR Jr, Salomão SR, et al. Development of an instrument to assess vision-related quality of life in young children. Am J Ophthalmol. 2004;138(3):362-72.

12. Salomão SR, Ventura DF. Large sample population age norms for visual acuities obtained with Vistech-Teller Acuity Cards. Invest Ophthalmol Vis Sci. 1995;36(3):657-70.

13. Birch EE, Cheng CS, Felius J. Validity and reliability of the Children's Visual Function Questionnaire (CVFQ). J AAPOS. 2007;11(5):473-9.

14. Pieh C, Fronius M, Chopovska Y, Pepler L, Klein M, Lüchtenberg M, et al. ["Fragebogen zum Kindlichen Sehvermögen (FKS)": Assessment of quality of life with the German version of the Children's Visual Function Questionnaire]. Ophthalmologe. 2008 Aug 2. [Epub ahead of print]. German. 